\title{
Metabolite Profile and Antioxidant Activity of Some Species of Genus Scutellaria Growing in Bulgaria
}

\author{
Yoana Georgieva ${ }^{1}$, Mariana Katsarova ${ }^{2}$, Plamen Stoyanov ${ }^{2} \mathbb{D}$, Rumen Mladenov ${ }^{2}$, Petko Denev ${ }^{3}$, \\ Desislava Teneva ${ }^{3}$, Evgeniy Plotnikov ${ }^{4}$ (D), Petko Bozov ${ }^{5}$ and Stela Dimitrova ${ }^{2,6, *}$
}

1 Department of Pharmacognosy and Pharmaceutical Chemistry, Faculty of Pharmacy,

Medical University of Plovdiv, 15A Vassil Aprilov, 4002 Plovdiv, Bulgaria; Yoana.Georgieva@mu-plovdiv.bg

2 Department of Bioorganic Chemistry, Faculty of Pharmacy, Medical University of Plovdiv, 15A Vassil Aprilov, 4002 Plovdiv, Bulgaria; Mariana.Katsarova@mu-plovdiv.bg (M.K.); plamen.stoyanov@mu-plovdiv.bg (P.S.); rummlad@uni-plovdiv.bg (R.M.)

3 Laboratory of Biologically Active Substances, Institute of Organic Chemistry with Centre of Phytochemistry—BAS, 139 Ruski, 4000 Plovdiv, Bulgaria; petko.denev@orgchm.bas.bg (P.D.); dteneva@orgchm.bas.bg (D.T.)

4 Research School of Chemistry and Applied Biomedical Sciences, Polytechnic University, 30 Lenin, 634050 Tomsk, Russia; plotnikov.e@mail.ru

5 Department of Biochemistry and Microbiology, Faculty of Biology, University of Plovdiv Paisii Hilendarski, 24 Tzar Asen, 4000 Plovdiv, Bulgaria; bozov@uni-plovdiv.bg

6 Research Institute, Medical University of Plovdiv, 15A Vassil Aprilov, 4002 Plovdiv, Bulgaria

* Correspondence: Stela.Dimitrova@mu-plovdiv.bg

Citation: Georgieva, Y.; Katsarova, M.; Stoyanov, P.; Mladenov, R.; Denev, P.; Teneva, D.; Plotnikov, E.; Bozov, P.; Dimitrova, S. Metabolite Profile and Antioxidant Activity of Some Species of Genus Scutellaria Growing in Bulgaria. Plants 2021, 10, 45. https://dx.doi.org/10.3390/ plants10010045

Received: 23 November 2020 Accepted: 23 December 2020 Published: 28 December 2020

Publisher's Note: MDPI stays neutral with regard to jurisdictional claims in published maps and institutional affiliations.

Copyright: () 2020 by the authors. Licensee MDPI, Basel, Switzerland. This article is an open access article distributed under the terms and conditions of the Creative Commons Attribution (CC BY) license (https: / / creativecommons.org/ licenses/by/4.0/).

\begin{abstract}
Until now, the interest to plants from genus Scutellaria in Bulgaria has been focused mainly on the terpenes in them. The purpose of this study is to enrich the information on the composition of the Bulgarian Scutellaria species in terms of both polyphenolic content as well as primary metabolites such as mono-, oligosaccharides and organic acids. An aerial part of three Scutellaria species growing in four low mountain regions of Southern Bulgaria was used. The flavonoids scutellarin, baicalin, baicalein, wogonin, wogonoside, luteolin, chrysin and a caffeoyl phenylethanoid glycoside-verbascoside have been identified via HPLC in different extracts from Scutellaria altissima, Scutellaria albida and Scutellaria galericulata. The antioxidant activity of the extracts has been evaluated. The Scutellaria altissima from Mezek and Scutellaria galericulata from Parvenets we studied, which are the richest in flavonoids (represented mainly by baicalin, scutellarin and wogonoside), show the highest Oxygen Radical Absorption Capacity. Hydroxyl Radical Averting Capacity of Scutellaria albida from Mezek and Scutellaria altissima from Bachkovo is the most pronounced, probably due to the content of scutellarin and luteolin and chrysin, respectively. Antioxidant activity of aqueous, methanolic and $70 \%$ and $96 \%$ ethanol extracts were also determined by the electrochemical method.
\end{abstract}

Keywords: Scutellaria; antioxidant activity; baicalin; carbohidrates; organic acids; scutellarin; wogonoside

\section{Introduction}

The genus Scutellaria belongs to one of the most widely used in traditional medicine and is the subject of many phytochemical studies of the plant family Lamiaceae. About 350 species are known to be common in East Asia, Europe and North America [1]. Scutellaria baicalensis is one of the most well-known and best-studied species, the roots of which have been used in traditional Chinese medicine for millennia [2]. Other species of this genus have also been used by many cultures for treatment of hypertension, atherosclerosis, inflammatory diseases, and have shown sedative, antioxidant, antimicrobial, anxiolytic, insecticidal, and antiviral properties [1]. This activity has been proven to be mainly due to secondary metabolites, which are synthesized by plants for a protective purpose [2,3]. Such are flavonoids [4], phenolic acids [5], phenylethanoid glycosides [6] and terpenes (neoclerrodanes [7], iridoids [8]) and act both individually and in combination. However, infor- 
mation on the composition of primary metabolites (sugars, organic acids, tocopherols [9] responsible for the development of the plants themselves is scarce. Organic acids are involved in several biochemical pathways, including energy production and formation of precursors for aminoacid biosynthesis [10]. Mono- and oligosaccharides, with low molecular weight, and their derivatives display a major role in the structure and function of the living cells [11]. They have been shown to affect primary and secondary metabolism, development and gene expression [12]. In their study, Park et al. demonstrated the influence of various carbohydrate sources on the type and amount of flavonoids accumulated in hairy root cultures of Scutellaria baicalensis [13]. The main group of biologically active compounds is undoubtedly the flavonoids and their glycosides [2]. They are natural antioxidants which act by neutralizing reactive oxygen species and chelating transition metal ions [14]. It is well documented that oxidative stress is involved in the etiology of a large number of human diseases, including diabetes, atherosclerosis, ischemia, neuropathological disorders such as Parkinson's and Alzheimer's disease, as well as the aging process [15] and natural antioxidants are being considered as prospective therapeutic agents.

In the flora of Bulgaria, genus Scutellaria is represented by 8 species: S. albida, S. alpina, S. altissima, S. columnae, S. galericulata, S. hastifolia, S. orientalis ssp. pinnatifida, S. velenovskyi [16]. Until now, the interest has been focused mainly on the terpenes in them. Neo-clerodane diterpenoids [17,18] were isolated and their antimicrobial [19] and antifeedant [20] activity demonstrated.

The purpose of this study is to enrich the information on the composition of the Bulgarian Scutellaria species in terms of both total polyphenolic and flavonoid content as well as primary metabolites such as mono- and oligosaccharides and organic acids. An aerial part of three Scutellaria species was used: S. albida, S. altissima and S. galericulata, growing in four low mountain regions of Southern Bulgaria. A comparative study of the composition of aqueous, methanol and ethanol extracts of the above Scutellaria species was made. The species-specific scutellarin, baicalin, baicalein, wogonin, wogonoside have also been identified and the antioxidant activity (AOA) of the extracts has been evaluated by three methods: Oxygen Radical Absorption Capacity (ORAC), Hydroxyl Radical Averting Capacity (HORAC) and electrochemical method.

\section{Results}

In the present study, a comparative research has been performed of the amounts of secondary (polyphenols and flavonoids) and primary (organic acids and carbohydrates) metabolites in the aerial part of three species of Scutellaria growing in four lowland regions of Southern Bulgaria as follows: Scutellaria altissima from the areas of Mezek(M) and Bachkovo(B), Scutellaria albida from Mezek(M) and Asenovgrad(A) and Scutellaria galericulata from Parvenets $(\mathrm{P})$. It is known that the biological activity of plants of this genus is mainly due to the phenolic compounds synthesized by them $[1,4]$. Table 1 presents our results, which show that there is a correlation $(r=0.96)$ between the obtained amounts of total polyphenols and total flavonoids. The total polyphenolic content varies from 1353.1 \pm 33.6 in S. albida(A) to $3498.5 \pm 61.6 \mathrm{mg} \mathrm{GAE} / 100 \mathrm{~g}$ dry $w t$ in S. altissima(M), and the total flavonoid content from $162.0 \pm 4.3$ to $747.2 \pm 5.8 \mathrm{mg}$ QE/100 $\mathrm{g}$ dry wt in S. albida(A) and in S. galericulata $(\mathrm{P})$, respectively. The amounts of individual flavonoids characteristic of the genus Scutellaria and extracted with different solvents are given in Figure 1. 
Table 1. Content of Phenolic and Flavonoid Compounds in Scutellaria Species.

\begin{tabular}{ccc}
\hline & \multicolumn{2}{c}{ Total Contents } \\
\cline { 2 - 3 } Scutellaria Species & $\begin{array}{c}\text { Polyphenols, } \\
\mathrm{mg} \mathrm{GAE}^{1} / 100 \mathrm{~g} \text { dry } w t\end{array}$ & $\begin{array}{c}\text { Flavonoids, } \\
\mathrm{mg} \mathrm{QE}^{2} / 100 \mathrm{~g} \text { dry } w t\end{array}$ \\
\hline S. altissima $(\mathrm{M})$ & $3498.5^{\mathrm{e}} \pm 61.6$ & $610.7^{\mathrm{c}} \pm 32.4$ \\
S. galericulata $(\mathrm{P})$ & $3256.5^{\mathrm{d}} \pm 87.8$ & $747.2^{\mathrm{d}} \pm 5.8$ \\
S. altissima $(\mathrm{B})$ & $2048.1^{\mathrm{c}} \pm 31.6$ & $296.4^{\mathrm{b}} \pm 24.9$ \\
S. albida $(\mathrm{M})$ & $1863.4^{\mathrm{b}} \pm 38.7$ & $255.6^{\mathrm{b}} \pm 10.9$ \\
S. albida (A) & $1353.1^{\mathrm{a}} \pm 33.6$ & $162.0^{\mathrm{a}} \pm 4.3$ \\
\hline
\end{tabular}

Results are presented as mean values \pm standard deviations. There are no significant differences among values marked with the same superscript letters in individual columns; ${ }^{1} \mathrm{GAE}$-gallic acid equivalent; ${ }^{2} \mathrm{QE}-$ quercetin equivalent.

(a)

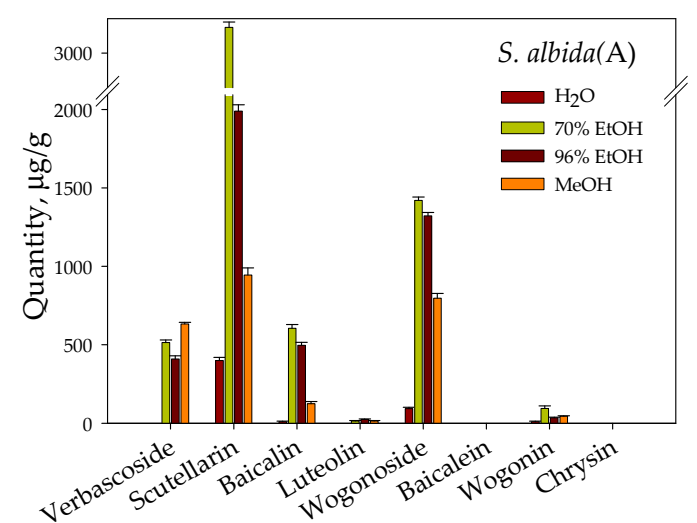

(c)

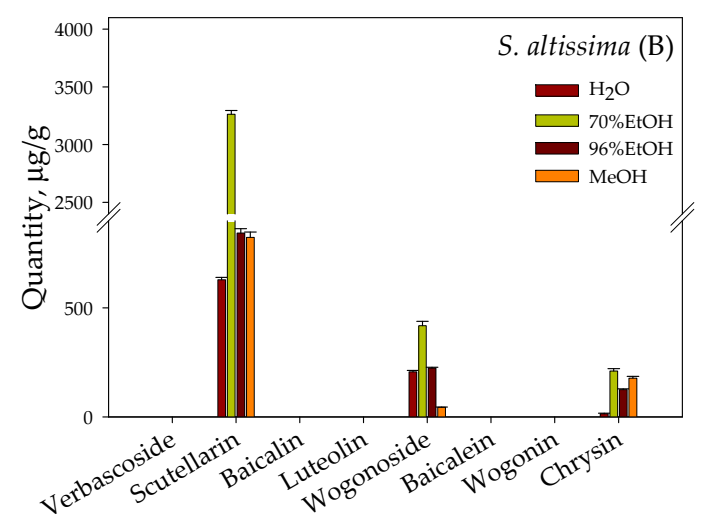

(b)

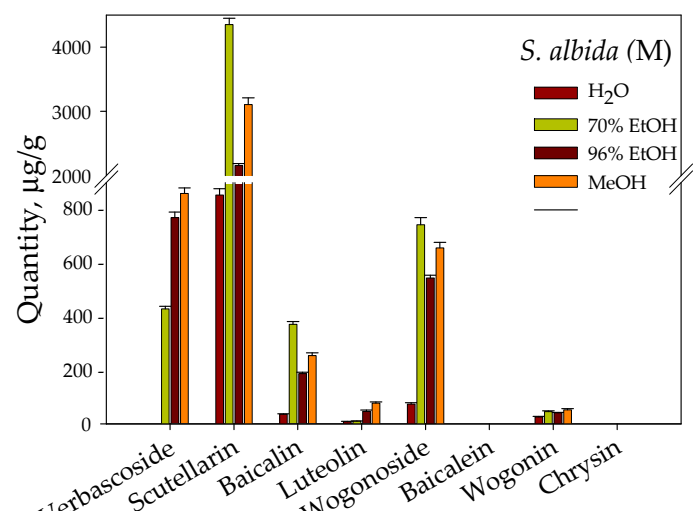

(d)

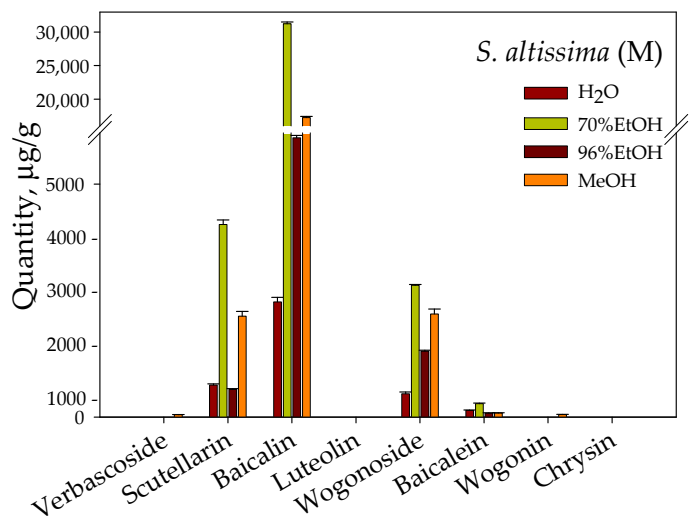

(e)

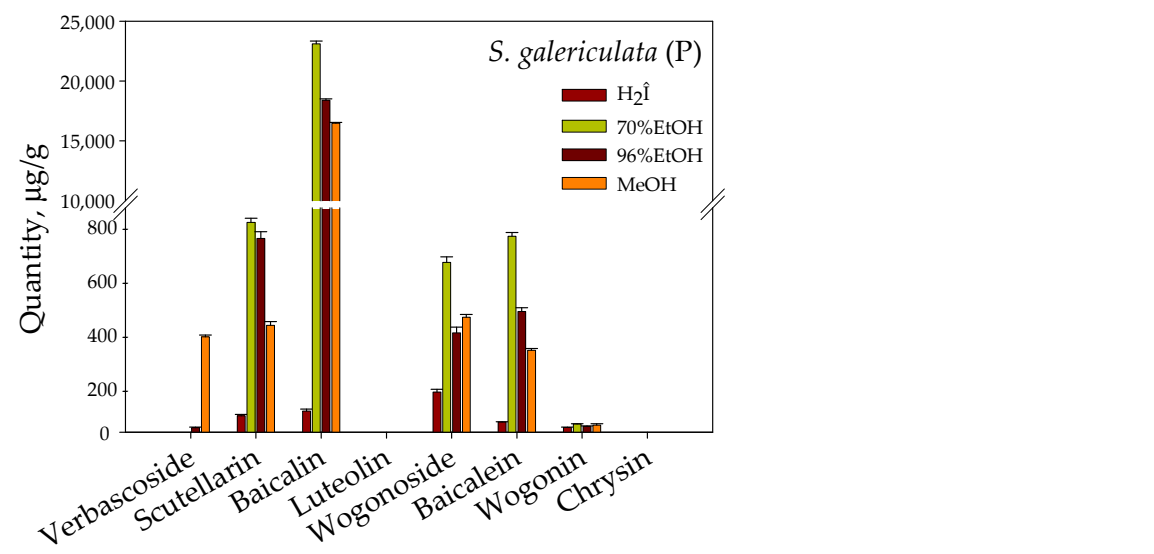

Figure 1. Content of Secondary Metabolites Determined by HPLC in Extracts from: (a) S. albida (A); (b) S. albida (M); (c) S. altissima (B); (d) S. altissima (M) and (e) S. galericulata (P) obtained with Different Solvents. 
Their extraction was performed with water, 70\% ethanol, 96\% ethanol and methanol. The most complete extraction of all flavonoids is achieved with $70 \%$ ethanol. Scutellarin is present in all samples with the highest amount in plant material of S. albida $(\mathrm{M})(4350 \mu \mathrm{g} / \mathrm{g})$ and S. altissima(M) $(4219 \mu \mathrm{g} / \mathrm{g})$ followed by S. altissima(B) $(3263 \mu \mathrm{g} / \mathrm{g})$ and S. albida(A) $(3075 \mu \mathrm{g} / \mathrm{g})$. Baicalin is contained in four of the five samples and its amount varies in a very wide range from 363 to $605 \mu \mathrm{g} / \mathrm{g}$ in S. albida(M) and S. albida(A) to 23,125-31,250 $\mu \mathrm{g} / \mathrm{g}$ in S. galericulata $(\mathrm{P})$ and S. altissima $(\mathrm{M})$. Wogonoside is found in the plant material of all studied species of Scutellaria from 419 to $2827 \mu \mathrm{g} / \mathrm{g}$, as well as wogonin, but in small quantities. However, wogonin is not found in S. altissima(B). Baicalein is found mainly in S. galericulata $(\mathrm{P})(1047 \mu \mathrm{g} / \mathrm{g})$ and in S. altissima $(\mathrm{M})(288 \mu \mathrm{g} / \mathrm{g})$. Verbascoside is present in the aerial part of S. albida(A), S. albida(M) and S. galericulata(P) and is best extracted with methanol.

The amounts of primary metabolites such as some mono-, disaccharides and organic acids have also been determined. Table 2 presents results for the content of fructose, glucose, galactose, rhamnose, xylose, fucose, sucrose, maltose and cellobiose, and Table 3 presents those of quinic, malic, ascorbic, citric, $\alpha$-ketoglutaric, succinic, oxalic and tartaric acids. S. albida $(\mathrm{M})$ shows the highest total carbohydrate content $(8290.8 \mathrm{mg} / 100 \mathrm{~g}$ dry $w t)$, while S. albida(A) contains a significant amount of organic acids $(9397.7 \mathrm{mg} / 100 \mathrm{~g}$ dry $w t)$.

Table 2. Content of Carbohydrates in Scutellaria Species.

\begin{tabular}{|c|c|c|c|c|c|}
\hline \multirow{2}{*}{$\begin{array}{l}\text { Carbohydrate, } \\
\text { mg/100g dry } w t\end{array}$} & \multicolumn{5}{|c|}{ Scutellaria Species } \\
\hline & S. albida(M) & S. albida (A) & S. altissima(B) & S. altissima $(\mathrm{M})$ & S. galericulata $(\mathrm{P})$ \\
\hline Fructose & $2160.5^{\mathrm{d}} \pm 173.1$ & $1584.5^{\mathrm{c}} \pm 118.5$ & $1095.1^{b} \pm 89.5$ & $1297.0^{b} \pm 109.7$ & $507.5^{\mathrm{a}} \pm 35.8$ \\
\hline Glucose & $2306.8^{b} \pm 203.7$ & $2319.7^{b} \pm 213.7$ & $2206.4^{b} \pm 190.6$ & $2148.7^{b} \pm 190.8$ & $901.4^{\mathrm{a}} \pm 65.1$ \\
\hline Galactose & $1137.2^{b} \pm 83.7$ & $1150.8^{b} \pm 91.1$ & $2238.0^{\mathrm{c}} \pm 183.8$ & $1035.4^{b} \pm 73.5$ & $384.3^{a} \pm 25.4$ \\
\hline Rhamnose & $203.2^{\mathrm{c}} \pm 12.3$ & $152.5^{b} \pm 9.3$ & $254.9^{d} \pm 15.5$ & $127.7^{\mathrm{a}} \pm 6.7$ & $157.9^{b} \pm 8.5$ \\
\hline Xylose & $1264.7^{d} \pm 106.5$ & $1012.5^{\mathrm{d}} \pm 93.3$ & $624.6^{c} \pm 52.5$ & $256.7^{b} \pm 18.7$ & $120.7^{\mathrm{a}} \pm 8.1$ \\
\hline Sucrose & $873.7^{b c} \pm 77.4$ & $1240.1^{\mathrm{d}} \pm 94.1$ & $756.9^{b} \pm 56.9$ & $590.8^{a} \pm 29.1$ & $1018.8^{\mathrm{cd}} \pm 90.9$ \\
\hline Cellobiose & $344.6^{\mathrm{a}} \pm 24.5$ & $337.3^{a} \pm 13.7$ & $546.9^{b} \pm 34.7$ & $806.5^{\mathrm{c}} \pm 50.6$ & $458.1^{b} \pm 27.8$ \\
\hline${ }^{1}$ Total & 8290.8 & 7797.4 & 7722.8 & 6262.8 & 3548.7 \\
\hline
\end{tabular}

Results are presented as mean values \pm standard deviations. There are no significant differences among values marked with the same superscript letters in individual rows. ${ }^{1}$ Total — sum of determined individual carbohydrates.

Table 3. Content of Organic Acids in Scutellaria Species.

\begin{tabular}{|c|c|c|c|c|c|}
\hline \multirow{2}{*}{$\begin{array}{c}\text { Acid, } \\
\mathrm{mg} / 100 \mathrm{~g} \text { dry } w t\end{array}$} & \multicolumn{5}{|c|}{ Scutellaria Species } \\
\hline & S. albida(A) & S. altissima (M) & S. altissima (B) & S. albida (M) & S. galericulata $(\mathrm{P})$ \\
\hline Quinic & $2918.9^{d} \pm 34.1$ & $222.4^{a} \pm 21.7$ & $1724.4^{\mathrm{c}} \pm 120.3$ & $413.4^{b} \pm 28.6$ & $203.1^{a} \pm 20.6$ \\
\hline Malic & $538.9^{b} \pm 26.6$ & $120.7^{a} \pm 10.5$ & $113.8^{a} \pm 12.0$ & $112.4^{\mathrm{a}} \pm 17.0$ & $115.3^{\mathrm{a}} \pm 11.8$ \\
\hline Ascorbic & $93.7^{b} \pm 5.3$ & $93.7^{b} \pm 5.3$ & $148.9^{c} \pm 10.9$ & $60.7^{\mathrm{a}} \pm 3.3$ & $91.1^{\mathrm{b}} \pm 6.4$ \\
\hline Citric & $267.3^{a} \pm 25.5$ & $1029.1^{c} \pm 57.1$ & $615.9^{b} \pm 28.6$ & $621.3^{b} \pm 46.1$ & $608.5^{b} \pm 53.7$ \\
\hline$\alpha$-Ketoglutaric & $259.8^{c} \pm 18.3$ & $86.4^{\mathrm{a}} \pm 8.7$ & $152.2^{b} \pm 13.9$ & $100.1^{\mathrm{a}} \pm 9.9$ & $132.1^{\mathrm{b}} \pm 8.9$ \\
\hline Succinic & $4823.2^{\mathrm{e}} \pm 124.8$ & $2538.5^{\mathrm{d}} \pm 152.8$ & $929.3^{b} \pm 35.9$ & $1803.7^{\mathrm{c}} \pm 114.1$ & $294.5^{a} \pm 27.6$ \\
\hline Oxalic & $495.9^{\mathrm{e}} \pm 10.4$ & $19.5^{b} \pm 1.6$ & $332.1^{\mathrm{d}} \pm 8.2$ & $67.9 \pm 3.7$ & $8.9^{a} \pm 0.2$ \\
\hline Tartaric & n.d. & $25.4^{b} \pm 2.7$ & $113.2^{c} \pm 6.0$ & $22.6^{b} \pm 1.7$ & $9.8^{a} \pm 0.7$ \\
\hline 1 Total & 9397.7 & 4148.4 & 4129.8 & 3220.1 & 1463.3 \\
\hline
\end{tabular}

Results are presented as mean values \pm standard deviations. There are no significant differences among values marked with the same superscript letters in individual rows; ${ }^{1}$ Total — sum of determined individual organic acids; n.d.—not detected.

Glucose is the main representative of carbohydrates. It is contained in the largest amount up to $2100 \mathrm{mg} / 100 \mathrm{~g}$ dry $w t$ in plant material from S. albida from Mezek and Asenovgrad as well as S. altissima from Mezek and Bachkovo. Of the acids, this is succinic 
acid, which is found in the largest amount in S. albida (A), S. albida (M) and S. altissima (M) in the range from $4823.2 \pm 124.8$ to $1803.7 \pm 114.1 \mathrm{mg} / 100 \mathrm{~g}$ dry $w t$.

Three methods were applied to determine the AOA of extracts from the studied Scutellaria species, namely ORAC, HORAC and electrochemical one. S. altissima $(\mathrm{M})$ and S. galericulata $(\mathrm{P})$ show the highest activity according to ORAC (1280.2 and $1155.2 \mu \mathrm{mol} \mathrm{TE} / \mathrm{g})$, S. albida (M) and S. altissima(B) (653.8 and $583.0 \mu \mathrm{mol} \mathrm{GAE/g)} \mathrm{according} \mathrm{to} \mathrm{HORAC} \mathrm{(Table} \mathrm{4)}$ and the methanol extract of S. albida $(\mathrm{M})(16.1 \mathrm{AOA})$ according to the electrochemical (Table 5).

Table 4. Oxygen Radical Absorption Capacity (ORAC) and Hydroxyl Radical Averting Capacity (HORAC) Antioxidant Activity of Extracts from Scutellaria Species.

\begin{tabular}{|c|c|c|}
\hline \multirow{2}{*}{ Scutellaria Species } & \multicolumn{2}{|c|}{ Antioxidant Activity } \\
\hline & $\mathrm{ORAC} \mu \mathrm{mol} \mathrm{TE}{ }^{1} / \mathrm{g}$ & $\mathrm{HORAC} \mu \mathrm{mol} \mathrm{GAE}^{2} / \mathrm{g}$ \\
\hline S. altissima $(\mathrm{M})$ & $1280.2^{c} \pm 79.7$ & $387.5^{c} \pm 29.4$ \\
\hline S. galericulata $(\mathrm{P})$ & $1155.2 \mathrm{~b}, \mathrm{c} \pm 119.2$ & $302.4^{b} \pm 27.2$ \\
\hline S. albida $(\mathrm{M})$ & $1005.6^{\mathrm{b}} \pm 68.8$ & $653.8^{\mathrm{d}} \pm 22.2$ \\
\hline S. altissima (B) & $926.9^{b} \pm 66.2$ & $583.0^{\mathrm{d}} \pm 32.1$ \\
\hline S. albida (A) & $652.3^{a} \pm 51.9$ & $201.3^{\mathrm{a}} \pm 12.4$ \\
\hline
\end{tabular}

Results are presented as mean values \pm standard deviations. There are no significant differences among values marked with the same superscript letters in individual columns; ${ }^{1} \mathrm{TE}$-trolox equivalent; ${ }^{2} \mathrm{GAE}$ - gallic acid equivalent.

Table 5. Antioxidant Activity (AOA) of Extracts from Scutellaria Species, as Measured by Electrochemical Method.

\begin{tabular}{|c|c|c|c|}
\hline Scutellaria Species & Extract & $\mathrm{K}, \mu \mathrm{mol} / \mathrm{L}$ per $\min \pm \mathrm{SD}$ & AOA \\
\hline \multirow{4}{*}{ S. altissima $(\mathrm{M})$} & $\mathrm{H}_{2} \mathrm{O}$ & $17.000^{\mathrm{c}} \pm 1.009$ & 5.8 \\
\hline & $70 \% \mathrm{EtOH}$ & $29.392^{b} \pm 2.043$ & 10.1 \\
\hline & $96 \% \mathrm{EtOH}$ & $22.824^{\mathrm{b}} \pm 2.134$ & 7.8 \\
\hline & $\mathrm{MeOH}$ & $31.481^{\mathrm{ab}} \pm 3.003$ & 10.8 \\
\hline \multirow{4}{*}{ S. albida (A) } & $\mathrm{H}_{2} \mathrm{O}$ & $8.368^{a} \pm 0.148$ & 2.9 \\
\hline & $70 \% \mathrm{EtOH}$ & $24.741^{\mathrm{a}} \pm 1.242$ & 8.5 \\
\hline & $96 \% \mathrm{EtOH}$ & $20.991^{b} \pm 2.213$ & 7.2 \\
\hline & $\mathrm{MeOH}$ & $34.811^{b} \pm 1.983$ & 11.9 \\
\hline \multirow{4}{*}{ S. albida (M) } & $\mathrm{H}_{2} \mathrm{O}$ & $10.055^{\mathrm{b}} \pm 0.654$ & 3.5 \\
\hline & $70 \% \mathrm{EtOH}$ & $23.192^{\mathrm{a}} \pm 1.842$ & 7.9 \\
\hline & $96 \% \mathrm{EtOH}$ & $20.263^{b} \pm 1.325$ & 6.9 \\
\hline & $\mathrm{MeOH}$ & $46.815^{\mathrm{c}} \pm 2.301$ & 16.1 \\
\hline \multirow{4}{*}{ S. galericulata (P) } & $\mathrm{H}_{2} \mathrm{O}$ & $9.924^{b} \pm 0.492$ & 3.4 \\
\hline & $70 \% \mathrm{EtOH}$ & $26.157^{\mathrm{a}} \pm 1.992$ & 8.9 \\
\hline & $96 \% \mathrm{EtOH}$ & $24.743^{b} \pm 2.891$ & 8.5 \\
\hline & $\mathrm{MeOH}$ & $43.784^{c} \pm 3.231$ & 15.0 \\
\hline \multirow{4}{*}{ S. altissima (B) } & $\mathrm{H}_{2} \mathrm{O}$ & $7.163^{a} \pm 1.016$ & 2.5 \\
\hline & $70 \% \mathrm{EtOH}$ & $22.981^{\mathrm{a}} \pm 1.194$ & 7.9 \\
\hline & $96 \% \mathrm{EtOH}$ & $22.706^{b} \pm 1.891$ & 7.8 \\
\hline & $\mathrm{MeOH}$ & $29.450^{a} \pm 0.990$ & 10.1 \\
\hline Trolox & $96 \% \mathrm{EtOH}$ & $2.911^{\mathrm{a}} \pm 0.010$ & 1.0 \\
\hline
\end{tabular}

Results are presented as mean values \pm standard deviations. There are no significant differences among values marked with the same superscript letters in individual rows.

\section{Discussion}

The qualities of medicinal plants are determined by the combination of active substances that they synthesize. This in turn depends on both the species itself and environmental factors such as temperature, light condition, and water status [21]. Regarding the 
influence of these factors on the flavonoid composition of plants from the genus Scutellaria, the information in the available literature is mainly for species baicalensis [22-24]. Scutellaria species growing in different areas at the foot of the Rhodope Mountains have been selected for the present study. It is noteworthy that $S$. altissima from both regions Mezek and Bachkovo and S. galericulata $(\mathrm{P})$ show a higher total amount of polyphenols and flavonoids compared to S. albida (Table 1). The amount of polyphenols in the order of about $3000 \mathrm{mg} \mathrm{GAE} / 100 \mathrm{~g}$ dry plant material obtained by us is similar to the results of Karolak et al., who studied cultured S. altissima [6]. However, they detect twice as many flavonoids as us. Higher total polyphenolic and flavonoid content in the dry extract of S. altissima compared to S. albida was also found by Vaiday et al., who studied 16 Scutellaria species cultivated in Georgia [25]. Şenol et al. studied 33 Scutellaria species from Turkey and reported a similar relationship between the amount of these biologically active substances in dry extracts of S. galericulata and S. albida [26]. In support of this, our results for specific flavonoids (Figure 1) show that only S. altissima $(\mathrm{M})$ and S. galericulata $(\mathrm{P})$ contain baicalein and almost 100 times more baicalin than the other samples tested. Interestingly, we recorded $31,250 \mu \mathrm{g} / \mathrm{g}$ baicalin in the aerial part of S. altissima $(\mathrm{M})$, while Karolak et al. found 22,570 $\mu \mathrm{g} / \mathrm{g}$ in the roots and only $270 \mu \mathrm{g} / \mathrm{g}$ in the stems (shoots) from 2 -year-old plants from S. altissima [6]. However, scutellarin is the one that is characteristic and present in all species studied by us, regardless of their habitat. In the plant material of S. albida from both regions, in addition to significant amounts of scutellarin, we also find the phenylethanoid glycoside-verbascoside, which was also identified by Matsa et al. [27] as well as luteoline-determined by Bardakci et al. [28] in S. albida subsp velenovskyi from the Karabük region of Turkey.

It is known that the AOA of plant extracts is due to phenolic compounds and especially to flavonoids in plant material. The S. altissima $(\mathrm{M})$ and S. galericulata $(\mathrm{P})$ we studied, which are the richest in polyphenols and flavonoids (represented mainly by baicalin, scutellarin and wogonoside), show the highest ORAC-assay AOA, respectively. This assay is based on the transfer of a hydrogen atom from the antioxidant to the peroxide radical. HORAC-assay takes into account the chelating ability of the antioxidant and according to it the AOA of S. albida $(\mathrm{M})$ and S. altissima $(\mathrm{B})$ is the most pronounced, probably due to the content of scutellarin and luteolin and chrysin, respectively. Baicalin, baicalein, and scutellarin are very strong antioxidants because the 6th position in nucleus A and $4^{\prime}$ in nucleus $\mathrm{B}$, in their molecules, contain OH-groups that are thought to contribute most for radical scavenging ability. AOA of aqueous, methanolic and $70 \%$ and $96 \%$ ethanol extracts was determined by electrochemical method. The extracts obtained with 70\% ethanol from all five samples contained the highest amount of biologically active substances and showed activity in the range from 7.9 to $10.1 \mathrm{AOA}$, again the highest being that of S. altissima(M). However, methanol extracts of S. albida $(\mathrm{M})$, S. galericulata $(\mathrm{P})$ and S. albida $(\mathrm{A})$ have been shown to be more active. This is probably due to the presence of verbascoside, which is best extracted with methanol and has strong antioxidant properties [29]. Karolak et al. also identified verbascoside in methanol extracts from shoot culture, in vitro-regenerated and in vivo-derived plants of S. altissima and determined their AOA by ABTS, FRAP and LPO assays. The authors confirmed that the total polyphenolic content correlated with the AOA determined by the three methods [6]. Lohani et al. determine the antioxidant potential of aqueous and ethanolic extract of S. lateriflora in mouse brain tissue and demonstrate a significant effect [30].

It turns out that while there is plenty of information about the secondary metabolites in the plants of the genus Scutellaria, there is not much data about the primary metabolites in them. Olennikov et al. isolate and characterize polysaccharides from the aerial part of S. baicalensis Georgi, in which they prove galactose, arabinose and glucose [31]. In addition, they determine their antioxidant activity by two methods- $\beta$-carotene bleaching assay and the DPPH method. There are reports in the available scientific literature of free radical scavenging ability of polysaccharides from fungi, plants and algae [32-34]. Hernandes-Marin and Martinez confirmed this ability in their theoretical study on some 
mono-(d-glucose, d-fructose), di-(sucrose, maltose) and trisaccharides (1-kestose, 6-kestose, raffinose) [11]. Our study sheds light on the carbohydrate content of Scutellaria genus plants growing in Bulgaria. We find the monosaccharides glucose, fructose, galactose, rhamnose, xylose and the disaccharides sucrose, cellobiose in a very wide concentration range (Table 2). Fructose is present in the largest amount in S. albida $(\mathrm{M})$, galactose-in S. altissima $(\mathrm{B})$ and glucose-in S. albida(A). According to a study by Park et al., they are extremely important for the biosynthesis of flavonoids. They investigated the optimal carbohydrate source in hairy root cultures of S. baicalensis infected with Agrobacterium rhizogenes strain and proved that $150 \mathrm{mM}$ sucrose in the culture medium increases the production of baicalein, fructose causes the greatest accumulation of baicalin and galactose- of wogonin [13].

It is important to know the composition of carbohydrates and organic acids, which are consumed directly, as infusions of plants can be easily prepared at home. As for the content of organic acids in the plants of the genus Scutellaria, again the data are only for $S$. baicalensis. Chirikova et al. monitor the accumulation of organic acids during the vegetation of the plant. They identified tartaric, citric, malic, malonic, succinic and fumaric acids in the aerial part of $S$. baicalensis Georgi and found that citric acid predominates and is detected in all phases of plant development [34]. The largest amount citric acid we find in S. altissima $(\mathrm{M})$. In contrast, we also determine the amounts of quinic, oxalic, $\alpha$-ketoglutaric and ascorbic acids. S. albida(A) contains the most succinic and quinic acids -4.8 and $2.9 \%$, respectively, and they have the largest contribution to the total amount of organic acids of $9.4 \%$ in it. It is highly likely that the ascorbic acid contained in S. altissima $(\mathrm{M})$ and S. altissima (B) contributes to the pronounced AOA of these two species.

The climatic specifics of the area where the medicinal plants grow inevitably affect the synthesis of biologically active substances. It is important to note that the flavonoids scutellarin, baicalin, baicalein, wogonin, wogoniside and a caffeoyl phenylethanoid glycoside - verbascoside, responsible for the therapeutic action of Scutellaria baicalensis (Baikal skullcap) and Scutellaria lateriflora (American skullcap) are found for the first time in species of the genus Scutellaria growing in Bulgaria. A consequence of the high polyphenolic and flavonoid content is the pronounced AOA of the studied species. Based on the shown antioxidant activity, pharmacological effects of extracts of some of the studied species can be sought, related to the reduction of oxidative stress. In order to obtain a more complete phytochemical profile of the studied Scutellaria species, in addition to determining the amounts of secondary metabolites contained in them, a comparative study of some primary metabolites, such as organic acids and carbohydrates, was performed.

\section{Materials and Methods}

\subsection{Chemicals}

Standards of flavonoids (scutellarin, baicalin, baicalein, wogonin, wogonoside, luteolin, chrysin), verbascoside, sugars (glucose, fructose, xylose, galactose, rhamnose, sucrose and cellobiose) and organic acids (quinic, malic, ascorbic, succinic, citric, $\alpha$-keto-glutaric, oxalic and tartaric), methanol and acetonitrile (HPLC gradient grade) were purchased from Sigma-Aldrich (Darmstadt, Germany). Water was obtained from Milipore Milli-Q Gradient water purification system (Barnstead, $\mathrm{NH}, \mathrm{US}$ ).

\subsection{Plant Material}

Aerial parts from three species of genus Scutellaria were collected during flowering in June 2017: Scutellaria altissima from the areas of Mezek and Bachkovo, Scutellaria albida from Mezek and Asenovgrad and Scutellaria galericulata from Parvenets. Collected raw materials were dried at $25^{\circ} \mathrm{C}$ and powdered. Plant materials were authenticated by prof. Rumen Mladenov. Voucher specimens for Scutellaria altissima (n.062641), Scutellaria albida (n.062861) and Scutellaria galericulata (n.062642) were deposited at the Herbarium of the University of Agriculture, Plovdiv, Bulgaria. 


\subsection{Extraction of Polyphenols}

Approximately $0.5 \mathrm{~g}$ of the dried powders were weighted accurately, transferred to extraction tubes and mixed with $40 \mathrm{~mL}$ of the extragent $(60 \%$ acetone solution in $0.5 \%$ formic acid) [35]. The extraction was conducted on an orbital shaker at room temperature for one $h$. Afterward, the samples were centrifuged $(6000 \times g)$ and supernatants were further used for antioxidant activity determination and analysis of total polyphenols and flavonoids.

\subsection{Determination of Total Phenolic/Flavonoid Contents}

The total polyphenols were colorimetrically determined with the Folin-Ciocalteu reagent according to the method of Singleton et al. [36]. Gallic acid was employed as a calibration standard and the results were expressed as mg gallic acid equivalents (GAE) per $100 \mathrm{~g}$ dry weight.

The total flavonoid content was determined with $\mathrm{AlCl}_{3}$ reagent according to Chang et al. [37]. The calibration curve was constructed with quercetin dihydrate $(10-200 \mathrm{mg} / \mathrm{L})$. The results are expressed as mg quercetin equivalents (QE) per $100 \mathrm{~g}$ dry weight.

\subsection{Extraction and HPLC Analysis of Individual Flavonoids}

Two percent solutions of plant material in distilled water, $70 \%$ ethanol, $96 \%$ ethanol and methanol, respectively, were prepared. The extraction was performed via maceration at room temperature $25{ }^{\circ} \mathrm{C}$ for $24 \mathrm{~h}$. The obtained extracts were filtered through a microfilter $(0.25 \mu \mathrm{m})$ and injected into the HPLC system. Verbascoside, scutellarin, baicalin, baicalein, wogonin, wogonoside, luteolin and chrysin were determined using the previously developed and validated HPLC method [38] on HPLC system (Varian, Australia) equipped with a ProStar230 solvent delivery module, photodiode array detector model 335 and HitachiC18 AQ $(250 \mathrm{~mm} \times 4.6 \mathrm{~mm}, 5 \mu \mathrm{m})$ column. The results are given as $\mu \mathrm{g} / \mathrm{g}$ dry weight.

\subsection{Extraction of Carbohydrates and Organic Acids}

One gram of the powders was weighted accurately and subjected to extraction with 30 $\mathrm{mL} \mathrm{3 \%}$ meta-phosphoric acid in distilled water for $1 \mathrm{~h}$ at $30^{\circ} \mathrm{C}$ and shaking on thermostatic water bath (NÜVE, Turkey). Afterward, the samples were centrifuged $(6000 \times g)$ and the supernatants were used for HPLC analysis of sugars and organic acids.

\subsection{HPLC Analysis of Carbohydrates/Organic Acids}

HPLC determination of glucose, fructose, xylose, galactose, rhamnose, sucrose and cellobiose was performed on Agilent 1220 HPLC system (Agilent Technology, USA), equipped with binary pump and Refractive Index Detector. Separation was performed using Aminex HPX-87H column $\left(300 \mathrm{~mm} \times 7.8 \mathrm{~mm}\right.$, BioRad), eluent $4 \mathrm{mM} \mathrm{H}_{2} \mathrm{SO}_{4}$, flow $0.5 \mathrm{~mL} / \mathrm{min}$, temperature $25^{\circ} \mathrm{C}$. Results are expressed as $\mathrm{mg} / 100 \mathrm{~g}$ dry weight.

HPLC determination of quinic, malic, ascorbic, succinic, citric, $\alpha$-keto-glutaric, oxalic and tartaric acids was performed on Agilent 1220 HPLC system (Agilent Technology, USA), equipped with binary pump and UV-Vis detector. Wavelength of $210 \mathrm{~nm}$ was used. Organic acid separation was performed using Agilent TC-C18 column $(250 \mathrm{~mm} \times 4.6 \mathrm{~mm}, 5 \mu \mathrm{m})$ at $25^{\circ} \mathrm{C}$. The mobile phase was $25 \mathrm{mM}$ phosphate $\left(\mathrm{K}_{2} \mathrm{HPO}_{4} / \mathrm{H}_{3} \mathrm{PO}_{4}\right)$ buffer $(\mathrm{pH} 2.4)$, flowing at $0.8 \mathrm{~mL} / \mathrm{min}$. Results are expressed as $\mathrm{mg} / 100 \mathrm{~g}$ dry weight.

\subsection{Determination of Antioxidant Activity}

\subsubsection{Oxygen Radical Absorbance Capacity (ORAC) Assay}

The method developed by Ou et al. was used with some modifications [39]. This method measures the ability of an antioxidant to neutralize peroxid radicals. It is based on the inhibition of the decline of fluorescence of fluorescein during its oxidation in the presence of an antioxidant. The thermal decomposition of 2,2'-azobis(2-amidinopropane) dihydrochloride (AAPH) is used as a peroxid radical generator. The results are expressed 
in $\mu$ mol Trolox equivalents per gram of extract. Measurements are performed on FLUOstar OPTIMA fluorometer (BMG LABTECH, Offenburg, Germany). The excitation wavelength of $485 \mathrm{~nm}$ and emission wavelength of $520 \mathrm{~nm}$ were used.

\subsubsection{Hydroxyl Radical Averting Capacity (HORAC) Assay}

The method was developed by Ou et al., and measures the ability of an antioxidant to form complexes in conditions of Fenton reaction, caused by the interaction between $\mathrm{Co}(\mathrm{II})$ and $\mathrm{H}_{2} \mathrm{O}_{2}$ [40]. The results are expressed in $\mu$ mol gallic acid equivalents per gram of extract. Measurements are performed on FLUOstar OPTIMA fluorometer (BMG LABTECH, Offenburg, Germany). The excitation wavelength of $485 \mathrm{~nm}$ and emission wavelength of $520 \mathrm{~nm}$ were used.

\subsubsection{Electrochemical Method for Determination of AOA}

The electrochemical method was used to determine the AOA [41]. The experiment's methodology consists in taking voltamperogram of cathodic electroreduction of oxygen using the "Analyst AOA" (RU.C.31.113.A N28715), connected to a PC. The AOA of the tested samples (extracts obtained with different solvents as described in 4.5.) was calculated according to kinetic criterion $\mathrm{K}$ (in micromoles per litre-minute) indicating the quantity of the reactive oxygen species in time, compared to the trolox kinetic criterion and expressed as:

$$
A O A=\frac{K_{\text {sample }}}{K_{\text {trolox }}}
$$

\subsection{Statistics}

The processing was repeated two times and the analysis performed at least in triplicate. Results were expressed as mean values \pm standard deviations. When needed, statistical comparisons were made using Duncan's multiple range test and Pearson correlation coefficient $(r)$ was used to express correlations. A $p$-value of $<0.05$ was taken to be significant. Statistical analysis was carried out using IBM SPSS 17.0.

Author Contributions: Conceptualization, S.D., P.B., and Y.G.; methodology, M.K., P.S., P.D., D.T., E.P., and P.B.; resources, Y.G., R.M., P.B., and S.D.; writing—original draft preparation, Y.G., M.K., and P.S.; writing-review and editing, P.D. and S.D.; supervision, S.D. All authors have read and agreed to the published version of the manuscript.

Funding: This study was supported by a research project № O1/2018 from 02.04.2018, granted by the Research council of Medical University of Plovdiv and managed by Dimitrova.

Institutional Review Board Statement: “Not applicable”.

Informed Consent Statement: "Not applicable".

Data Availability Statement: The data presented in this study are available on request from thecorresponding author.

Acknowledgments: We would like to thank Alexandrina Delova for the revision of the English translation.

Conflicts of Interest: The authors declare no conflict of interest. The funders had no role in the design of the study; in the collection, analyses, or interpretation of data; in the writing of the manuscript, or in the decision to publish the results.

\section{References}

1. Shang, X.; He, X.; He, X.; Li, M.; Zhang, R.; Fan, P.; Zhang, Q.; Jia, Z. The genus Scutellaria an ethnopharmacological and phytochemical review. J. Ethnopharmacol. 2010, 128, 279-313. [CrossRef] [PubMed]

2. Wang, Z.-L.; Wang, S.; Kuang, Y.; Hu, Z.-M.; Qiao, X.; Min, Y. A comprehensive review on phytochemistry, pharmacology, and flavonoid biosynthesis of Scutellaria baicalensis. Pharm. Boil 2018, 56, 465-484. [CrossRef] [PubMed]

3. Zhao, Q.; Chen, Y.; Martin, C. Scutellaria baicalensis, the golden herb from the garden of Chinese medicinal plants. Sci. Bull. 2016, 61, 1391-1398. [CrossRef]

4. Tungmunnithum, D.; Thongboonyou, A.; Pholboon, A.; Yangsabai, A. Flavonoids and Other Phenolic Compounds from Medicinal Plants for Pharmaceutical and Medical Aspects: An Overview. Medicines 2018, 5, 93. [CrossRef] 
5. Bejenaru, C.; Mogoşanu, G.D.; Bejenaru, L.E.; Biţă, A.; Bălşeanu, T.-A.; Ionică, F.E. Effect of Scutellariae herba extracts in experimental model of skin burns: Histological and immunohistochemical assessment. Rom. J. Morphol. Embryol. 2016, 57, 1285-1294. [PubMed]

6. Grzegorczyk-Karolak, I.; Kuz'ma, Ł.; Wysokin'ska, H. Study on the chemical composition and antioxidant activity of extracts from shoot culture and regenerated plants of Scutellaria altissima L. Acta Physiol. Plant. 2015, 37, 1736-1740. [CrossRef]

7. Bruno, M.; Piozzi, F.; Rosselli, S. Natural and hemisynthetic neoclerodane diterpenoids from Scutellaria and their antifeedant activity. Nat. Prod. Rep. 2002, 19, 357-378. [CrossRef]

8. Gousiadou, C.; Karioti, A.; Heilmann, J.; Skaltsa, H. Iridoids from Scutellaria albida ssp. Albida. Phytochem. 2007, 68, 1799-1804. [CrossRef]

9. Roriz, C.L.; Barros, L.; Carvalho, A.-M.; Ferreira, I.C.F.R. HPLC-Profiles of Tocopherols, Sugars, and Organic Acids in Three Medicinal Plants Consumed as Infusions. Int. J. Food Sci. 2014, 2014, 1-5. [CrossRef]

10. Lopez-Bucio, J.; Nieto-Jacobo, M.F.; Ram '1rez-Rodr'1guez, V.; Herrera-Estrella, L. Organic acid metabolism in plants: From adaptive physiology to transgenic varieties for cultivation in extreme soils. Plant Sci. 2000, 160, 1-13. [CrossRef]

11. Hernandez-Marin, E.; Martínez, A. Carbohydrates and Their Free Radical Scavenging Capability: A Theoretical Study. Phys. Chem. 2012, 16, 9668-9675. [CrossRef] [PubMed]

12. Gibson, S. Plant sugar-response pathways. Part of a complex regulatory web. Plant Physiol. 2000, 124, 1532-1539. [CrossRef] [PubMed]

13. Park, C.; Kim, Y.; Li, X.; Kim, H.; Arasu, M.; Al-Dhabi, N.; Leed, S.; Park, S. Influence of Different Carbohydrates on Flavonoid Accumulation in Hairy Root Cultures of Scutellaria baicalensis. Nat. Prod. Commun. 2016, 11, 799-802. [CrossRef] [PubMed]

14. Kumar, S.; Pandey, A. Chemistry and biological activities of flavonoids: An Overview. Sci. World J. 2013, 2013, 16. [CrossRef]

15. Halliwell, B. Are polyphenols antioxidants or pro-oxidants? What do we learn from cell culture and in vivo studies? Arch. Biochem. Biophys. 2008, 476, 107-112. [CrossRef]

16. Delipavlov, D.; Cheshmedzhiev, I.; Popova, M.; Terzijski, D.; Kovatchev, I. Key to the Plant in Bulgaria; Acad. Press Agrar. Univ.: Plovdiv, Bulgaria, 2003; p. 591. (In Bulgarian)

17. Bozov, P.; Malakov, P.; Papanov, G.; de la Torre, M.; Rodríguez, B.; Perales, A. Scutalpin A, a neo-clerodane diterpene from Scutellaria alpina. Phytochemistry 1993, 34, 453-456. [CrossRef]

18. Bozov, P.; Penchev, P.; Vasileva, T.; Iliev, I. Diterpenoids from Scutellaria galericulata. Chem. Nat. Comp. 2014, 49, 479-480. [CrossRef]

19. Bozov, P.; Girova, T.; Prisadova, N.; Hristova, Y.; Gochev, V. Antimicrobial Activity of neo-Clerodane Diterpenoids isolated from Lamiaceae Species against Pathogenic and Food Spoilage Microorganisms. Nat. Prod. Commun. 2015, 10, 1797-1800. [CrossRef] [PubMed]

20. Bozov, P.; Georgieva, Y. Antifeedant Activity of Neo-clerodane Diterpenoids from Scutellaria altissima against Colorado Potato Beetle Larvae. Nat. Prod. Commun. 2017, 12, 327-328. [CrossRef]

21. Bray, E. Molecular responses to water deficit. Plant Physiol. 1993, 103, 1035-1040. [CrossRef]

22. Chen, S.; Yuan, Y.; Luo, Y.; Huang, L.; Li, X. Effects of light on flavonoids accumulation and related gene expression in suspension cultures of Scutellaria baicalensis. China J. Chin. Mat. Med. 2010, 35, 49-52.

23. Yuan, Y.; Liu, Y.; Luo, Y.; Huang, L.; Chen, S.; Yang, Z.; Qin, S. High temperature effects on flavones accumulation and antioxidant system in Scutellaria baicalensis Georgi cells. Afr. J. Biotech. 2011, 10, 5182-5192.

24. Yuan, Y.; Liu, Y.; Wu, C.; Chen, S.; Wang, Z.; Yang, Z.; Qin, S.; Huang, L. Water deficit affected flavonoid accumulation by regulating hormone metabolism in Scutellaria baicalensis Georgi roots. PLoS ONE 2012, 7, e42946. [CrossRef] [PubMed]

25. Vaidya, B.; Brearley, T.; Joshee, N. Antioxidant Capacity of Fresh and Dry Leaf Extracts of Sixteen Scutellaria Species. JMAP 2014, $2,42-49$.

26. Senol, F.; Orhan, I.; Yilmaz, G.; Cicek, M.; Sener, B. Acetylcholinesterase, butyrylcholinesterase, and tyrosinase inhibition studies and antioxidant activities of 33 Scutellaria L. taxa from Turkey. Food Chem. Toxicol. 2010, 48, 781-788. [CrossRef] [PubMed]

27. Matsa, M.; Bardakci, H.; Gousiadoua, C.; Kirmizibekmez, H.; Skaltsa, H. Secondary metabolites from Scutellaria albida L. ssp. velenovskyi (Rech. f.) Greuter \& Burdet. Biochem. Syst. Ecol. 2019, 83, 71-76.

28. Bardakci, H.; Acar, E.T.; Kırmızibekmez, H. Simultaneous quantification of six flavonoids in four Scutellaria taxa by HPLC-DAD method. Rev. Bras. Farmacogn. 2019, 29, 17-23. [CrossRef]

29. Georgiev, M.; Alipieva, K.; Orhan, I.; Abrashev, R.; Denev, P.; Angelova, M. Antioxidant and cholinesterases inhibitory activities of Verbascum xanthophoeniceum Griseb. and its phenylethanoid glycosides. Food Chem. 2011, 128, 100-105. [CrossRef]

30. Lohani, M.; Ahuja, M.; Buabeid, M.A.; Schwartz, D.; Shannon, D.; Suppiramaniam, V.; Kemppainen, B.; Dhanasekaran, M. Anti-oxidative and DNA Protecting Effects of Flavonoids-rich Scutellaria lateriflora. Nat. Prod. Commun. 2013, 8, 1415-1418. [CrossRef]

31. Olennikov, D.; Chirikova, N.; Tankhaeva, L. Lamiaceae carbohydrates. IV. Water- soluble polysaccharides from Scutellaria baicalensis. Chem. Nat. Compd. 2008, 44, 556-559. [CrossRef]

32. Nishizawa, A.; Yabuta, Y.; Shigeoka, S. Galactinol and Raffinose Constitute a Novel Function to Protect Plants from Oxidative Damage. Plant Physiol. 2008, 147, 1251-1263. [CrossRef] [PubMed]

33. Kong, F.; Zhang, M.; Liao, S.; Yu, S.; Chi, J.; Wei, Z. Antioxidant Activity of Polysaccharide-enriched Fractions Extracted from Pulp Tissue of Litchi Chinensis Sonn. Molecules 2010, 15, 2152-2165. [CrossRef] [PubMed]

34. Chirikova, N.K.; Olennikov, D.N.; Rokhin, A. Organic acids from medicinal plants. 4. Scutellaria baicalensis. Chem. Nat. Compd. 2008, 44, 84-85. [CrossRef]

35. Kratchanova, M.; Denev, P.; Ciz, M.; Lojek, A.; Mihailov, A. Evaluation of the antioxidant activity of medicinal plants containing polyphenol compounds. Comparison of two extraction systems. Acta Biochim. Pol. 2010, 57, 229-234. [CrossRef] [PubMed] 
36. Singleton, V.; Rossi, J. Colorimetry of total phenolics with phosphomolybdic-phosphotungstic acid reagents. Am. J. Enol. Vitic. 1965, 16, 144-158

37. Chang, C.; Yang, M.; Wen, H.; Chern, J. Estimation of total flavonoid content in propolis by complementary colorimetric methods. J. Food Drug Anal. 2002, 10, 178-182.

38. Georgieva, Y.; Katsarova, M.; Gercheva, K.; Bozov, P.; Dimitrova, S. HPLC analysis of flavonoids from Scutellaria altissima. Bulgarian. Chem. Commun. Spec. Issue D 2019, 5, 119-123.

39. Ou, B.; Hampsh-Woodill, M.; Prior, R. Development and validation of an improved oxygen radical absorbance capacity assay using fluorescein as the fluorescent probe. J. Agric. Food Chem. 2001, 49, 4619-4626. [CrossRef]

40. Ou, B.; Hampsch-Woodill, M.; Flanagan, J.; Deemer, E.; Prior, R.; Huang, D. Novel fluorometric assay for hydroxyl radical prevention capacity using fluorescein as the probe. J. Agric. Food Chem. 2002, 50, 2772-2777. [CrossRef]

41. Korotkova, E.; Karbainov, Y.; Shevchuk, A. Study of antioxidant properties by voltammetry. J. Electroanal. Chem. 2002, 518, 56-60. [CrossRef] 